\title{
Indústria moveleira e dinâmica demográfica de Ubá, Minas Gerais
}

\author{
Furniture industry and demographic dynamics of Ubá, Minas \\ Gerais, Brazil
}

\author{
Vitor Juste dos Santos ${ }^{1}$ \\ Pedro José de Oliveira Machado 2
}

\begin{abstract}
Resumo
O presente estudo busca relacionar a influência das principais atividades econômicas desenvolvidas no município de Ubá, Minas Gerais, com sua dinâmica demográfica, desde a segunda metade do século XIX até as primeiras décadas do século XXI, destacando o papel desempenhado pela indústria moveleira. Também objetiva mostrar as consequências do crescimento da população urbana na paisagem da cidade, transformada ao longo do século XX e início do XXI. Para isso, foi feita uma revisão de literatura sobre a evolução histórica de Ubá e, em seguida, os resultados dessa revisão foram relacionados com dados de população disponibilizados nos sites do Instituto Brasileiro de Geografia e Estatística e do Ipeadata. A substituição da prática da agricultura de subsistência pelas produções de café, e posteriormente o fumo, foram de grande importância para o desenvolvimento municipal. No entanto, a indústria de móveis se tornou, e continua sendo, a atividade mais significativa no município, tanto em termos econômicos quanto demográficos, tendo grande impacto na modificação da paisagem urbana na segunda metade do século XX e no início do século XXI.
\end{abstract}

Palavras-chave: Atividades Econômicas. Evolução Demográfica. Microrregião de Ubá. Migração. Móveis.

\begin{abstract}
The present study seeks to relate the influence of the main economic activities developed in the city of Ubá, MG, with its demographic dynamics, from the second half of the nineteenth century to the first decades of the twenty-first century, highlighting the role played by the furniture industry. It also aims to show the consequences of urban population growth in the city landscape, transformed throughout the 20th and early 21st centuries. For this, a literature review was done on the historical evolution of Ubá, relating this review with population data obtained in Instituto Brasileiro de Geografia e Estatística and Ipeadata website. The substitution of subsistence farming practices for coffee production, and later tobacco production, was of great importance for municipal development. However, the furniture industry has become, and continues to be, the most significant activity in the municipality, both economically and demographically. It also had a great impact on the modification of the urban landscape in the second half of the 20th century and beginning of the 21 st century.
\end{abstract}

\footnotetext{
${ }^{1}$ Universidade Federal de Viçosa, Minas Gerais, Brasil. vjustedossantos@gmail.com

2 Universidade Federal de Juiz de Fora, Minas Gerais, Brasil. pjomachado@gmail.com

Artigo recebido em: 17/01/2018. Aceito para publicação em: 10/05/2019.
} 
Keywords: Demographic Evolution. Economic Activities. Furniture. Microregion of Ubá. Migration.

\section{Introdução}

O presente estudo busca relacionar a influência das principais atividades econômicas desenvolvidas no município de Ubá, Minas Gerais, com sua dinâmica demográfica, desde a segunda metade do século XIX até as primeiras décadas do século XXI, destacando o papel desempenhado pela indústria moveleira. Também objetiva mostrar as consequências do crescimento da população urbana na paisagem da cidade, significativamente transformada ao longo do século XX e início do século XXI.

Embora aborde o caso específico de Ubá, várias considerações feitas neste artigo refletem a realidade vivida em grande parte das cidades médias do país. Esses centros urbanos cresceram mais que as cidades a eles subordinadas, ou seja, atraíram populações das pequenas cidades ao seu redor. Cidades como Ubá são atrativas para as populações das cidades menores de sua região, por oportunizar melhores condições de acesso a serviços elementares, mais chances de emprego, entre outros benefícios (IBGE, 2008). Assim, as populações das cidades médias cresceram significativamente nas últimas décadas, principalmente devido à emigração das populações das cidades menores.

Ubá reflete bem a situação da maioria dos municípios brasileiros que presenciaram sua população rural migrar para as cidades, especialmente na década de 1960, o que refletiu nos resultados do Censo Demográfico de 1970 (IBGE, 1970), quando a população urbana brasileira superou o contingente rural (BRITO, 2006).

Ubá possui características peculiares que favorecem constantes relações econômicas com cidades menores e com o espaço microrregional a ela ligado. Sua localização também favorece as relações econômicas com centros 
maiores (AMORIM FILHO; RIGOTTI; CAMPOS, 2007; IBGE, 2008), pois dista $290 \mathrm{~km}$ de Belo Horizonte, $300 \mathrm{~km}$ do Rio de Janeiro, $580 \mathrm{~km}$ de São Paulo e 470 km de Vitória. Além de estar situada a cerca de 100 km de alguns centros regionais importantes de Minas Gerais, como Juiz de Fora, Barbacena, Muriaé e Viçosa.

Este artigo tem caráter introdutório nas discussões sobre a evolução demográfica no município, uma vez que inexistem trabalhos específicos sobre esse tema, podendo assim se tornar referência para pesquisas futuras.

\section{Atividades econômicas predominantes em Ubá}

Pode-se diferenciar quatro períodos principais em relação às atividades econômicas dominantes no município de Ubá: 1) Agricultura de subsistência; 2) Monocultura de Café; 3) Cultura de Tabaco e 4) Indústria moveleira. (Figura 1).

A agricultura de subsistência era a atividade que se destacava desde o início da formação do município. Já na segunda metade do século XIX, a expansão do café até o Vale do Paraíba fez com que esta produção ganhasse importância na região, com a agricultura de subsistência sendo substituída gradativamente. A monocultura de café, voltada para a exportação, se torna a atividade econômica mais importante (ALBINO, 2009; INTERSIND, 2014).

Concomitante ao café, havia a produção de fumo de rolo ou de corda (OLIVEIRA JÚNIOR, 2011), milho e, em menor quantidade, de cebola, produções importantes regionalmente. Com a crise cafeeira, em finais da década de 1920, a produção fumageira cresce de importância, dominando a economia local entre as décadas de 1930 e 1950. A partir daí, o fumo começou a ser rejeitado no mercado regional devido à sua baixa combustibilidade (ALBINO, 2009; INTERSIND, 2014). A rejeição do produto se deu em virtude do uso inadequado, por muitos anos seguidos, de insumos e adubos, 
comprometendo a qualidade do fumo. Nesse período, Ubá era conhecida em todo o país como o maior consumidor de insumos e adubos e também como o maior produtor de fumo. Como consequência, no final dos anos de 1950, a crise da produção fumageira deixou grande número de pessoas sem trabalho nas fazendas e na cidade (OLIVEIRA et al., 2010).

Figura 1. Relação entre evolução demográfica e atividades econômicas do município de Ubá, no período de 1872 a 2010.

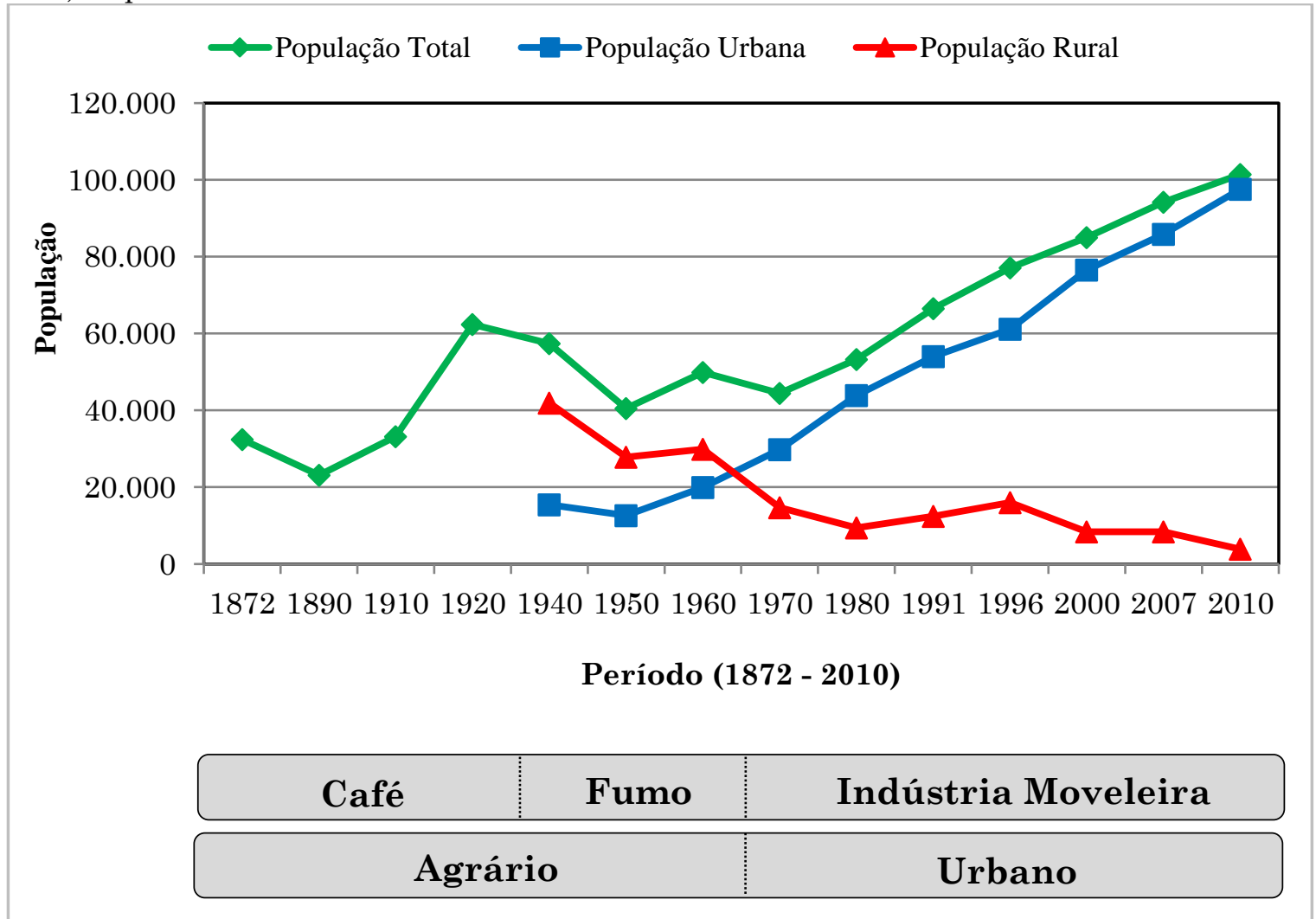

Fonte: Ipeadata (2014), ALBINO (2009), ANDRADE (1961); OLIVEIRA et al. (2010). Org.: os autores;

Nota: A prática da agricultura de subsistência não foi apresentada neste gráfico devido à falta de dados populacionais anteriores ao período de 1872 .

A perda da significância da produção de fumo fez crescer o desemprego em Ubá, tornando-se necessário buscar novas atividades econômicas que absorvessem os desempregados, sendo o setor moveleiro o mais promissor (INTERSIND, 2014). 
O setor de móveis foi o mais propício a se desenvolver devido a algumas razões. Primeiramente, a atividade de marcenaria existia em Ubá desde o início do século XX e está relacionada à entrada de imigrantes italianos que, além de mão de obra para trabalhar nas lavouras de café e de fumo, trouxeram a vocação profissional para a manufatura. Assim, ao longo desse século foram aos poucos surgindo empresas relacionadas ao setor. Em 1917 foi aberta a primeira marcenaria para a produção de esquadrias e móveis sob encomenda. Em 1927, outra empresa começou a produzir e a comercializar malas e móveis de forma consignada. Em 1947 foi aberta uma fábrica de vassouras, e em 1957, outra empresa, a Auto-Refrigeração, iniciou a fabricação de refrigeradores de madeira em série (OLIVEIRA et al., 2010).

No entanto, o setor moveleiro realmente passou a se destacar a partir da década de 1960, como alternativa à crise econômica que a cidade e a região passaram a enfrentar em decorrência da queda da produção de fumo. Em 1959, Francisco Parma fundou a Domani, a primeira fábrica de armários de cozinha laqueados. Tais armários eram feitos a partir de caixotes de madeira desmontados, fornecidos pelo Armarinho Santo Antônio, uma grande empresa comercial que adquiria grande quantidade de mercadorias, desde produtos alimentícios até vestuários para posterior distribuição em Ubá e região. Posteriormente, na Domani, passou-se a fabricar armários, guardaroupas, sofás e esquadrias a partir de matéria prima importada (OLIVEIRA et al., 2010).

Outros fatores destacados por Oliveira et al. (2010) foram essenciais para o crescimento das indústrias de móveis, sendo eles: a) O interesse da Associação Comercial e Industrial de Ubá (ACIU) em desenvolver atividades industriais no município para a absorção da mão de obra rural disponível; b) A existência de indústrias moveleiras, como a Auto-Refrigeração e a Domani; c) A criação, em 1963, de uma diretoria paralela à ACIU, responsável por tratar dos problemas relacionados à precariedade da comunicação, à escassez da energia elétrica, ao asfaltamento da rodovia Ubá/Juiz de Fora e, ainda, à 
obtenção de linha de crédito no Banco do Brasil; d) A promoção, por parte da ACIU, de feiras e mostras, objetivando promover o parque manufatureiro, de modo a incentivar a criação de empresas industriais na cidade e região. A primeira mostra ocorreu em 1963 e a segunda em 1964.

A partir de então, as empresas do setor de móveis cresceram de forma significativa na cidade. Por meio de financiamentos, a Domani ampliou sua capacidade de produção e venda, chegando a contratar 1.200 pessoas, exercendo um papel de grande importância no crescimento e desenvolvimento do polo moveleiro local (ALBINO, 2009; SILVA, 2008).

A Domani encerra suas atividades em meados da década de 1970. Como consequência, muitos dos trabalhadores que foram dispensados decidiram abrir seus próprios negócios, aproveitando-se do conhecimento adquirido em relação à produção e à comercialização e do grande número de mão de obra disponível. A tecnologia e a localização favoreceram o desenvolvimento dessa atividade (SILVA, 2008).

No final da década de 1970, houve um acréscimo significativo do número de indústrias no setor moveleiro, com 25 novas empresas. Na década de 1980 esse número aumentou para 72 empresas (OLIVEIRA et al., 2010). No final da década de 2000, o número de empresas aumentou para 410 (ALVES, 2009).

Percebe-se, portanto, que além da tradição em trabalhar com marcenaria trazida pelos imigrantes italianos, além das várias empresas ligadas a este setor que existiam ao longo do século $\mathrm{XX}$, houve uma preocupação, principalmente por parte da iniciativa privada, em promover o desenvolvimento industrial em Ubá. Como a atividade marceneira vinha se destacando, o desenvolvimento das indústrias de móveis seria o mais promissor para os empresários da época (INTERSIND, 2014; SILVA, 2008). Por meio dos dados populacionais obtidos no endereço eletrônico do Instituto de Pesquisa Econômica Aplicada (IPEA) (IPEADATA, 2014), observa-se, a partir da década de 1960, um aumento significativo da população urbana, 
acompanhado por uma considerável diminuição da população rural, o que coincide com o desenvolvimento da indústria moveleira na cidade.

\section{A influência da indústria moveleira no crescimento da população urbana}

Como pode ser observado na Figura 1, até a década de 1960, o contingente demográfico municipal passou por grande variação, ora crescendo, ora decrescendo.

Houve uma diminuição entre os Censos de 1872 e 1890, seguido de um período de crescimento intenso, entre 1890 e 1920, de outro decréscimo, de 1920 a 1950, e outro período de crescimento entre 1950 e 1960. Entre 1960 e 1970, houve outro decréscimo demográfico, sendo a última queda registrada da população total do município.

Relacionando a Figura 2 com a Tabela 1, nota-se que o acréscimo e o decréscimo da população total de Ubá foram sendo condicionados ao desmembramento do município, pela emancipação de seus distritos, até que, a partir de 1970, quando o território municipal não passou mais por mudanças, a população total cresceu de forma contínua.

No entanto, a partir de meados da década de 1960, a indústria moveleira se torna a atividade econômica mais importante para a cidade, constituindo-se como um fator de atração populacional. Isso é demonstrado na Figura 1, quando Ubá, a partir da década de 1970, torna-se um município com população urbana superior a população rural. 
Figura 2. Transformação do território municipal de Ubá/MG a partir de 1872.

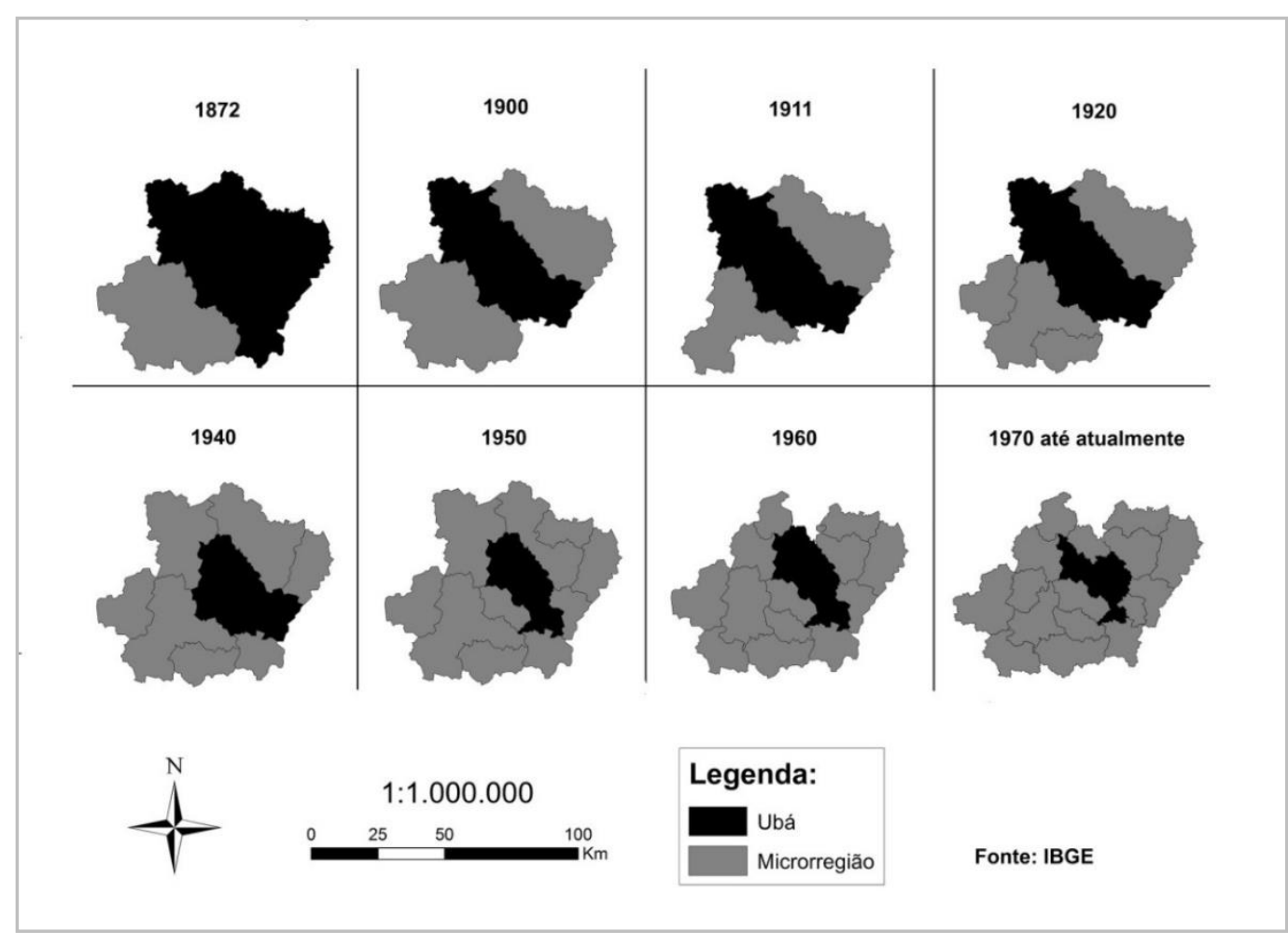

Org.: dos autores. Fonte: Arquivos vetoriais disponíveis em:

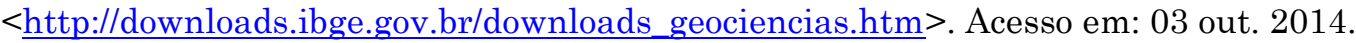

Tabela 1. Municípios emancipados de Ubá

$\begin{array}{cc}\text { Municípios Emancipados (Ano) } & \text { População Perdida } \\ \text { Visconde do Rio Branco (1881) } & 18.295 \\ \text { Senador Firmino (1938) } & 18.604 \\ \text { Guidoval (1948) } & 10.063 \\ \text { Tocantins (1948) } & 10.519 \\ \text { Divinésia (1962) } & 4.375 \\ \text { Rodeiro (1962) } & 4.308\end{array}$

Org.: dos autores. Fonte: IBGE Cidades (2015).

Quando a empresa Domani encerra suas atividades e muitos de seus empregados abrem seus próprios negócios, registra-se um crescimento do número de empresas do setor, porém de forma desorganizada. A produção apresentava características artesanais, com pouca tecnologia. Os empresários não possuíam conhecimento suficiente e resistiam a qualquer tentativa de reunião para troca de informações, temendo que suas estratégias fossem 
copiadas pelos concorrentes. Visto que isso era um problema, alguns empresários indicaram a necessidade da criação de um sindicato do setor (OLIVEIRA et al., 2010).

Em junho de 1986 foi criada a Associação dos Fabricantes de Móveis de Ubá, formada por 20 empresas, que posteriormente, em 1989, teve o nome modificado para Sindicato Intermunicipal das Indústrias Moveleiras de Ubá (INTERSIND, 2014). A instituição tinha como objetivo organizar as ações do setor no sentido de auxiliar os empresários na busca de soluções para o crescimento do polo moveleiro (SILVA, 2008).

A partir da década de 1990, as indústrias do setor passaram por uma grande capacitação de pessoal e de empresários, além de investimentos na renovação do parque de máquinas e equipamentos. Muitos trabalhos foram desenvolvidos em prol da indústria de móveis, como a organização de sindicatos e associações, a instalação de instituições para formação de mão de obra e tecnologia, como o Serviço Nacional de Aprendizagem Industrial (SENAI), além da realização de feiras de móveis, máquinas e matérias-primas (OLIVEIRA et al., 2010; SILVA, 2008).

Esse crescimento da indústria moveleira na cidade, juntamente com os fornecedores de matéria-prima e tecnologias, fez com que o meio urbano se tornasse mais atrativo para as pessoas.

Dessa forma, percebe-se através dos dados populacionais do município, que o êxodo rural, principalmente a partir da década de 1960 foi muito intenso, havendo consequente crescimento da população urbana. Juntamente com as melhorias da expectativa de vida e os avanços na área da saúde, a população urbana de Ubá cresceu de forma significativa, alcançando 97.599 pessoas no último censo demográfico do Instituto Brasileiro de Geografia e Estatística (IBGE, 2010).

O crescimento da população total do município e de sua população urbana está relacionado com a saída das pessoas das áreas rurais. Contudo, 
a migração de pessoas dos municípios da microrregião também deve ser considerada, como pode ser observado na Tabela 2.

Tabela 2. Evolução demográfica da microrregião de Ubá entre 1940 e 2010.

\begin{tabular}{ccccccccc}
\hline Município/Ano & 1940 & 1950 & 1960 & 1970 & 1980 & 1991 & 2000 & 2010 \\
Astolfo Dutra & 9.993 & 11.858 & 14.538 & 11.119 & 10.513 & 11.412 & 11.805 & 13.049 \\
Divinésia & - & - & - & 4.375 & 3.132 & 3.009 & 3.188 & 3.293 \\
Dores do Turvo & - & - & 5.313 & 5.335 & 4.841 & 5.043 & 4.799 & 4,462 \\
Guarani & 9.379 & 8.049 & 8.390 & 10.063 & 7.884 & 8.046 & 8.520 & 8.678 \\
Guidoval & - & 10.063 & 11.143 & 10.158 & 7.249 & 7.177 & 7.490 & 7.206 \\
Guiricema & 17.219 & 16.964 & 15.318 & 13.933 & 10.443 & 10.297 & 9.259 & 8.707 \\
Mercês & 13.925 & 10.138 & 10.201 & 9.637 & 10.119 & 10.074 & 10.061 & 10.368 \\
Piraúba & - & - & 8.571 & 10.274 & 10.251 & 9.142 & 11.140 & 10.862 \\
Rio Pomba & 24.528 & 26.169 & 16.607 & 14.588 & 14.057 & 14.884 & 16.359 & 17.110 \\
Rodeiro & - & - & - & 4.308 & 3.244 & 3.749 & 5.375 & 6.876 \\
São Geraldo & - & 10.648 & 10.325 & 9.758 & 7.521 & 7.860 & 7.716 & 10.263 \\
Senador Firmino & 18.604 & 16.036 & 6.587 & 6.754 & 6.757 & 6.241 & 6.598 & 7.230 \\
Silveirânia & - & - & - & 2.699 & 2.075 & 2.047 & 2.138 & 2.192 \\
Tabuleiro & - & - & 5.866 & 5.356 & 4.791 & 4.361 & 4.572 & 4.079 \\
Tocantins & - & 10.519 & 13.547 & 14.346 & 13.158 & 12.836 & 15.005 & 15.823 \\
Ubá & 57.394 & 40.516 & 49.874 & 44.503 & 53.311 & 66.511 & 84.987 & 101.446 \\
V. do Rio Branco & 39.867 & 26.179 & 24.642 & 25.206 & 26.257 & 28.451 & 32.598 & 37.492 \\
Microrregião & 190.909 & 187.139 & 200.922 & 202.412 & 195.603 & 211.140 & 241.610 & 269.136 \\
\hline
\end{tabular}

Org: dos autores. Fonte: Ipeadata (2014).

Nota-se, que a partir da década de 1970, quando a microrregião tomou a configuração territorial que apresenta atualmente, o município de Ubá foi o único que apresentou crescimento populacional considerável, passando de 44.503 habitantes para 101.446 em quatro décadas. Ou seja, um aumento de 128\%, 56.943 pessoas, mais que dobrando sua população. Além de Ubá, somente Visconde do Rio Branco obteve um aumento demográfico significativo, passando de 25.206 para 37.492 habitantes em 40 anos, um aumento de 12.286 pessoas (49\%).

Os outros 15 municípios da microrregião não apresentaram aumentos consideráveis de suas populações, sendo que sete deles tiveram taxas negativas de crescimento entre 1970 e 2010. Devido a isso, Ubá concentrava, em 2010, 37,70\% da população da microrregião, enquanto o mais próximo, Visconde do Rio Branco, concentrava 13,94\%. 
Percebe-se, portanto, que enquanto os municípios de sua microrregião seguem estagnados em relação ao crescimento de suas populações ou possuem crescimentos baixos, Ubá possui um aumento constante e significativo, diferenciando-se consideravelmente em termos demográficos.

A área urbana de Ubá vem sendo um atrativo para pessoas de outros municípios. O Censo de 2010 (IBGE, 2010), em relação aos dados migratórios do município, mostrou que 6.143 pessoas, de cinco anos ou mais de idade, não residiam em Ubá até 31/07/2005. Ou seja, todo esse contingente se mudou em cinco anos, entre 2005 e 2010. Desse total, 5.744 foram para a área urbana e 398 para a área rural, o que demonstra a atratividade da cidade.

Seguindo a tendência da população total, a população urbana de Ubá teve um acréscimo significativo de 1970 a 2010, em relação aos municípios da microrregião (Figura 3). Quanto à população rural (Figura 4), observa-se uma situação oposta para o município de Ubá. De 1970 a 2010 houve uma queda acentuada, principalmente a partir de 1996, o que é um reflexo dos investimentos feitos na indústria moveleira a partir da década de 1990, como já mencionado, aumentando o poder de atração da área urbana.

Além de Ubá, outros municípios também tiveram quedas significativas de suas populações rurais, como Visconde do Rio Branco, Guiricema e Tocantins. No entanto, essa redução não foi acompanhada de um aumento expressivo da população urbana, com exceção de Visconde do Rio Branco.

Os outros sete municípios também tiveram queda de suas populações rurais, mas sem aumento de suas populações urbanas, o que resultou no decréscimo de suas populações totais (Tabela 2). 
Figura 3. Evolução da população urbana dos municípios da microrregião de Ubá entre 1970 e 2010.

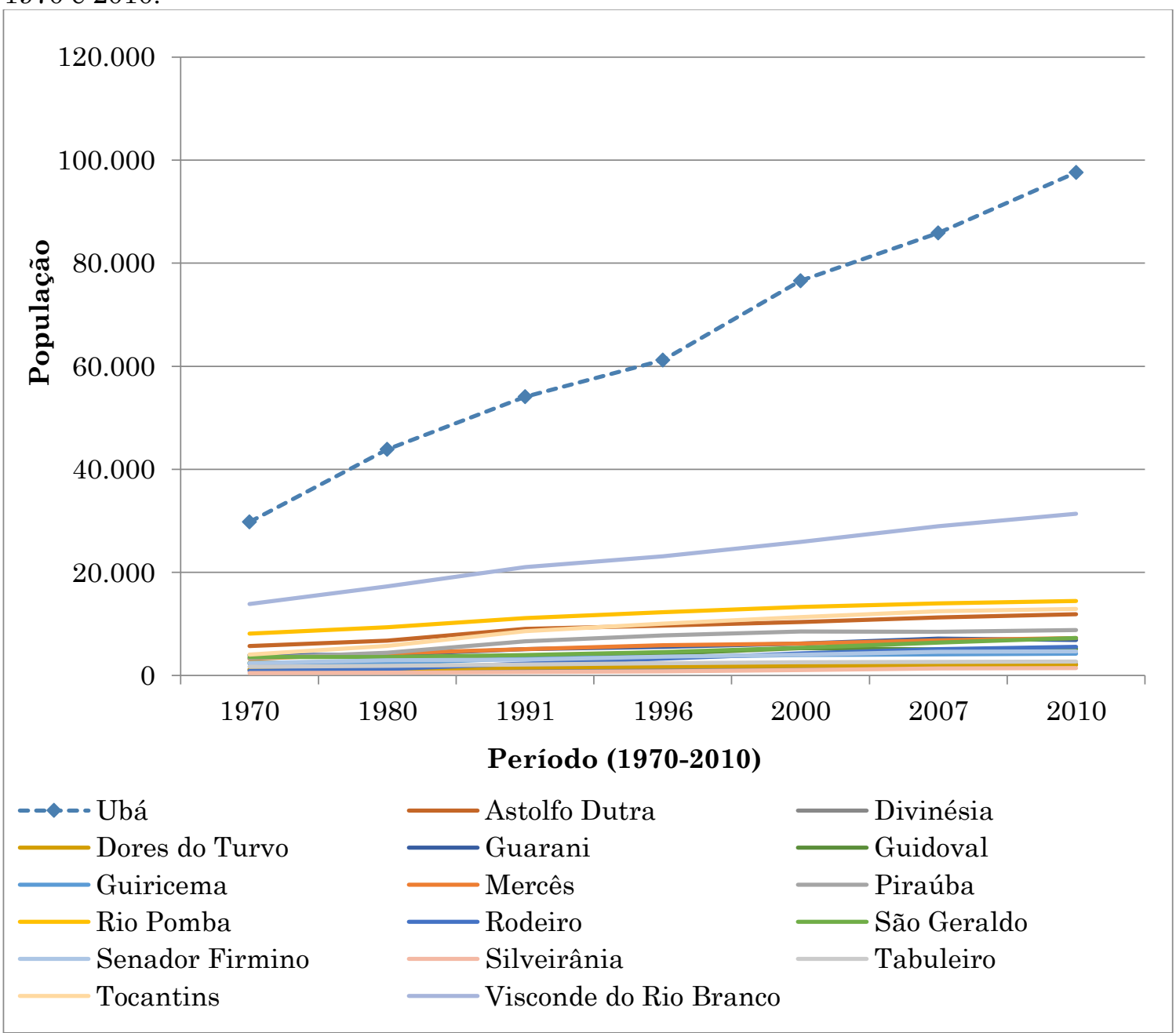

Org: dos autores. Fonte: Ipeadata (2014).

Outros dados disponíveis no endereço eletrônico do IBGE demonstram o esvaziamento das áreas rurais na microrregião (IBGE; 1985, 1995, 2006). O número de pessoal ocupado em estabelecimentos agropecuários passou de 37.679 , em 1985, para 20.265, em 2006 , o que representa $46 \%$ de decréscimo (17.414 pessoas) (Tabela 3). Desses, Ubá contribuiu com 3.941 pessoas.

Tais dados demonstram como a agricultura e a pecuária vem tendo menor importância econômica no município e na microrregião, perdendo espaço para os serviços urbanos. 
Figura 4. Evolução da população rural dos municípios da microrregião de Ubá entre 1970 e 2010.

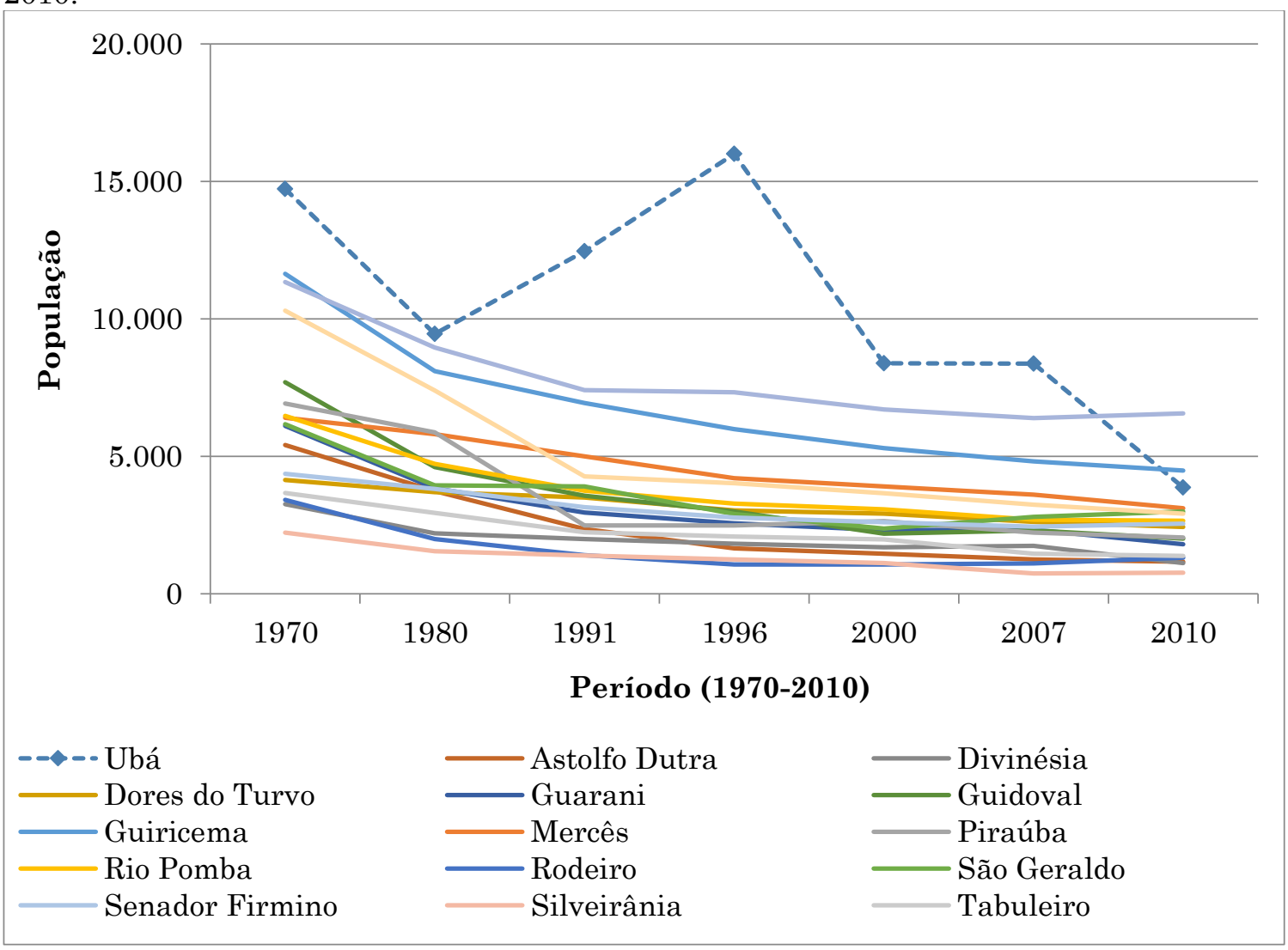

Org: dos autores. Fonte: Ipeadata (2014).

Tabela 3. Pessoal ocupado em estabelecimentos agropecuários entre 1970 e 2006.

\begin{tabular}{ccccccc}
\hline Local/Ano & 1970 & 1975 & 1980 & 1985 & $1995 / 1996$ & 2006 \\
& & & & & & \\
Ubá & 5.069 & 4.390 & 4.305 & 5.664 & 3.625 & 1.723 \\
Microrregião & $\mathbf{3 5 . 2 2 9}$ & $\mathbf{3 6 . 5 5 1}$ & $\mathbf{3 3 . 9 7 0}$ & $\mathbf{3 7 . 6 7 9}$ & $\mathbf{2 9 . 8 0 2}$ & $\mathbf{2 0 . 2 6 5}$ \\
\hline
\end{tabular}

Org.: dos autores. Fonte: Censos Agropecuários do IBGE, anos de 1970, 1975, 1980, 1985, 1995/1996 e 2006.

Em contrapartida, a indústria e o setor de serviços possuem maior representatividade na economia regional, apesar de em seis municípios o setor agropecuário ainda ter maior importância do que o industrial. Porém, a microrregião de Ubá segue a tendência do Estado de Minas Gerais e do Brasil, com o Produto Interno Bruto (PIB) sendo mais influenciado pela indústria e pelos serviços (Tabela 4). 
Tabela 4. Produto interno bruto (PIB) dos municípios da microrregião de Ubá, de Minas Gerais e do Brasil.

$\begin{array}{cccc}\text { Municípios } & & \text { Setores } & \\ \text { Astolfo Dutra } & \text { Agropecuária } & \text { Indústria } & \text { Serviços } \\ \text { Divinésia } & 9.154 & 60.402 & 90.496 \\ \text { Guarani } & 4.276 & 3.930 & 17.885 \\ \text { Guidoval } & 14.139 & 32.407 & 51.816 \\ \text { Guiricema } & 11.058 & 14.776 & 37.901 \\ \text { Mercês } & 21.226 & 13.505 & 45.665 \\ \text { Piraúba } & 12.205 & 10.977 & 53.806 \\ \text { Rio Pomba } & 13.104 & 12.014 & 61.083 \\ \text { Rodeiro } & 17.198 & 39.542 & 118.695 \\ \text { São Geraldo } & 3.544 & 60.955 & 57.176 \\ \text { Silveirânia } & 7.322 & 28.213 & 49.915 \\ \text { Tabuleiro } & 5.387 & 1.911 & 12.728 \\ \text { Tocantins } & 6.817 & 5.201 & 22.120 \\ \text { Ubá } & 13.450 & 29.339 & 104.492 \\ \text { Visconde do Rio Branco } & 21.684 & 439.681 & 874.312 \\ \text { Microrregião } & 17.939 & 276.840 & 314.905 \\ \text { Minas Gerais } & \mathbf{1 7 8 . 5 0 3} & \mathbf{1 . 0 2 9 . 6 9 3} & \mathbf{1 . 9 1 2 . 9 9 5} \\ \text { Brasil } & \mathbf{1 5 . 5 6 8 . 0 4 8} & \mathbf{5 4 . 3 0 6 . 1 8 3} & \mathbf{1 . 1 9 7 . 7 7 4 . 0 0 1}\end{array}$

Org: dos autores. Fonte: IBGE Cidades (2015).

Nota-se como o PIB de Ubá na indústria e nos serviços é significativamente superior em relação aos outros municípios da microrregião. Já em relação ao setor agropecuário, essa superioridade não é tão acentuada, o que mostra como esse setor perdeu importância no município e como a indústria e os serviços dominam a economia local.

Ubá segue uma tendência de forte crescimento populacional. Analisando as estimativas de população das cidades da microrregião, de 1991 para 2015, observa-se o que seu crescimento demográfico vai continuar superior aos de seus vizinhos (Figura 5). Enquanto as populações de Ubá e Visconde do Rio Branco crescem de forma mais acelerada, o restante dos municípios segue estagnado em relação ao crescimento demográfico. 
Esse crescimento demográfico de Ubá vem provocando uma expansão da cidade de forma acelerada, pois é na área urbana que se demonstra mais significativo, enquanto que nas áreas rurais a tendência é de queda da população.

Figura 5. Evolução da população dos municípios da microrregião de Ubá, entre 1991 a 2015 , segundo as estimativas populacionais do IBGE.

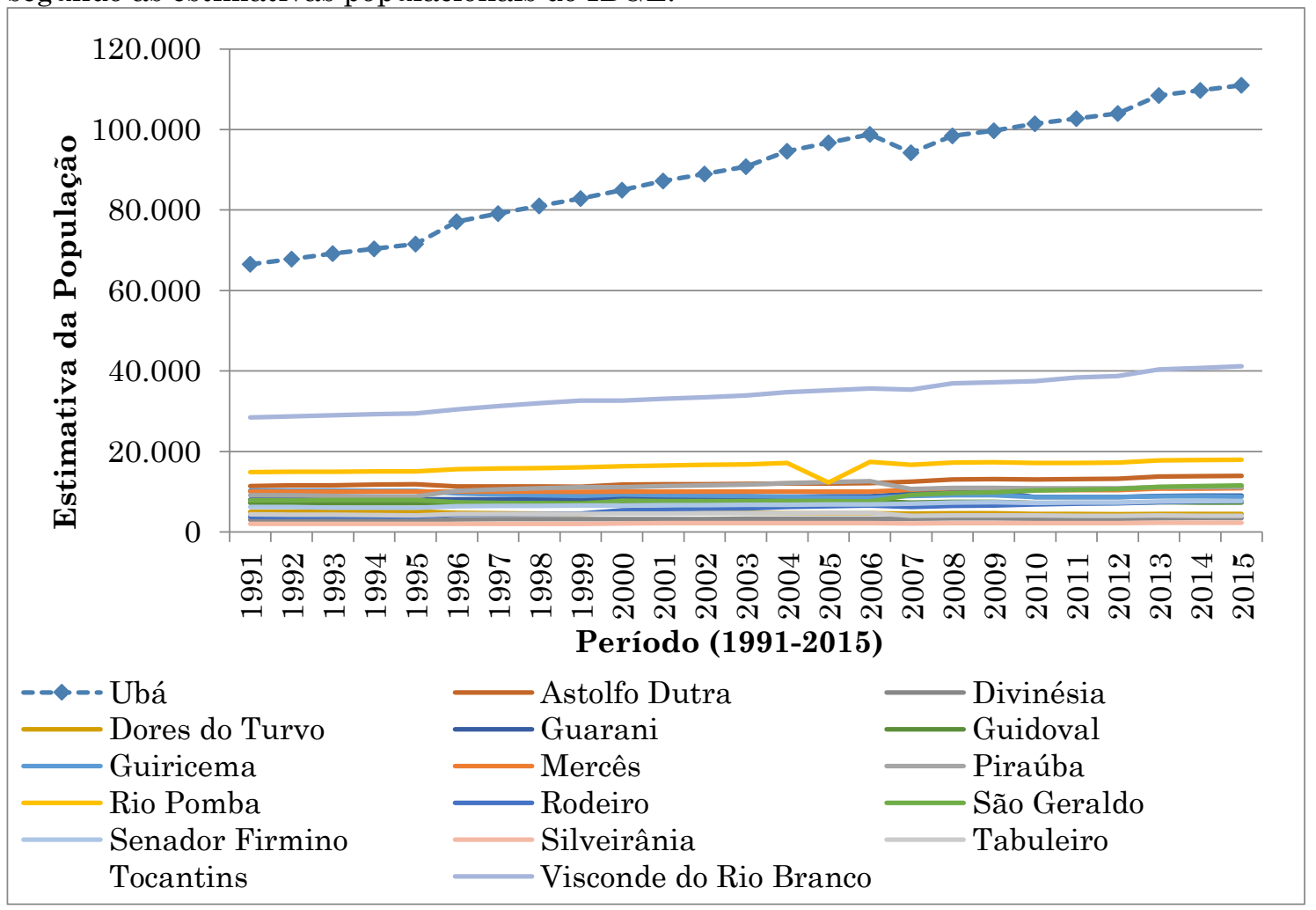

Org: dos autores. Fonte: IBGE Cidades (2015).

Crescimento da população urbana e mudança da paisagem da cidade

O acréscimo demográfico registrado desde a década de 1970 e que segue em ritmo acelerado, faz com que o contexto atual se diferencie significativamente daquele que existia à época em que Andrade (1961) realizou sua pesquisa no município, em finais da década de 1950. Esse autor destacou que as habitações e outras construções da cidade de Ubá se 
localizavam nos vales fluviais, próximos aos cursos d'águas, evitando subir as encostas devido às dificuldades de construção e de abastecimento de água.

Porém, devido aos avanços no setor da construção civil e nas tecnologias de distribuição de água, além do intenso processo de ocupação das áreas de vales até a década de 1970, as novas habitações passaram a subir as vertentes adjacentes, pois o crescimento demográfico acentuado gerou forte demanda por novos espaços no sítio original.

No final do século XX e início do XXI, a visualização de ocupações em áreas de encostas e topos de morros se tornou comum na paisagem. $\mathrm{O}$ setor imobiliário se tornou atrativo no município, devido à demanda por novas ocupações pela população crescente.

Os dados demográficos obtidos no endereço eletrônico do Ipeadata (2014) demonstram como Ubá vem atraindo pessoas, pois de 1970 a 2010 houve um aumento de $33,75 \%$ para $43,10 \%$ da concentração da população da microrregião nesse município. Ou seja, mais de um terço da população urbana da microrregião reside na cidade de Ubá (Tabela 5).

Tabela 5. Concentração da população urbana da microrregião em Ubá.

\begin{tabular}{|c|c|c|c|c|c|c|c|c|}
\hline & Ino & 1970 & 1980 & 1991 & 1996 & 2000 & 2007 & 2010 \\
\hline \multirow[t]{2}{*}{$\begin{array}{c}\text { População } \\
\text { Urbana }\end{array}$} & Ubá & $\begin{array}{c}29.782 \\
(33,75 \%)\end{array}$ & $\begin{array}{c}43.860 \\
(38,82 \%)\end{array}$ & $\begin{array}{c}54.051 \\
(37,97 \%)\end{array}$ & $\begin{array}{c}61.162 \\
(38,02 \%)\end{array}$ & $\begin{array}{c}76.602 \\
(40,68 \%)\end{array}$ & $\begin{array}{c}85.858 \\
(41,35 \%)\end{array}$ & $\begin{array}{c}97.599 \\
(43,10 \%)\end{array}$ \\
\hline & Microrregião & 88.247 & 112.984 & 142.361 & 160.864 & 188.314 & 207.613 & 226.475 \\
\hline
\end{tabular}

Org: dos autores. Fonte: Ipeadata (2014)..

Esse acréscimo de 67.817 pessoas, em 40 anos, na área urbana, tem como contrapartida, no mesmo período, um decréscimo de 14.721 na área rural. Isso significa que, em 2010, $96,19 \%$ da população morava na cidade e $3,81 \%$ nas áreas rurais.

Somando-se o perímetro urbano de todos os distritos (Diamante de Ubá, Miragaia e Ubarí) e da sede do município de Ubá, resulta um valor total 
de $98,70 \mathrm{~km}^{2}$, ou seja, 24,22\% do território municipal são áreas urbanas. $\mathrm{O}$ restante, $308,80 \mathrm{~km}^{2}(75,78 \%)$ são espaços rurais. Os limites destes perímetros urbanos foram definidos em 2009 (PMU, 2011).

Em 2010, com população de 101.446 residentes, o município possuía uma densidade demográfica de 248,96 hab/ $\mathrm{km}^{2}$. Porém, quando se trata somente da população que reside nas áreas urbanas, tal densidade se eleva para $988,84 \mathrm{hab} / \mathrm{km}^{2}$. É claro que quando se trata dos diferentes locais, tal densidade será diferenciada, como, por exemplo, os distritos de Ubá, que possuem populações inferiores à sede.

Mas esses dados servem para demonstrar como a população municipal está concentrada em áreas urbanas, pois quando se trata das áreas rurais, a densidade demográfica é de apenas $12,52 \mathrm{hab} / \mathrm{km}^{2}$. Ou seja, há uma diferença de 976,32 habitantes ocupando um quilômetro quadrado quando se compara as áreas urbanas e rurais, no ano de 2010. Essa diferença deverá se tornar maior se considerarmos os 111.012 habitantes estimados para 2015 e a tendência do acréscimo de pessoas na cidade e do decréscimo no campo.

Como pode ser visto na Figura 6, a mancha urbana aumentou consideravelmente entre 1985 e 2011. Isso é devido ao crescimento da população urbana nesse período, pois de 43.860 pessoas em 1980, Ubá passou a ter 97.599 pessoas na área urbana em 2010, o que corresponde a um acréscimo de 53.739 (122,52\%) em três décadas.

Percebe-se que o crescimento da cidade acompanha os vales, seguindo os cursos d’água, e ocupando as áreas de várzeas, lançando "tentáculos" (ANDRADE, 1961) em direção dos vales fluviais que circulam as colinas (Figura 7). No entanto, essa expansão não se limitou somente aos vales fluviais, devido à intensa ocupação deles. Ela se espraiou para as encostas dos morros adjacentes, ocupando vertentes que em alguns casos possuem altas declividades (Figura 8). 
Figura 6. Crescimento da mancha urbana de Ubá entre 1985 a 2011.

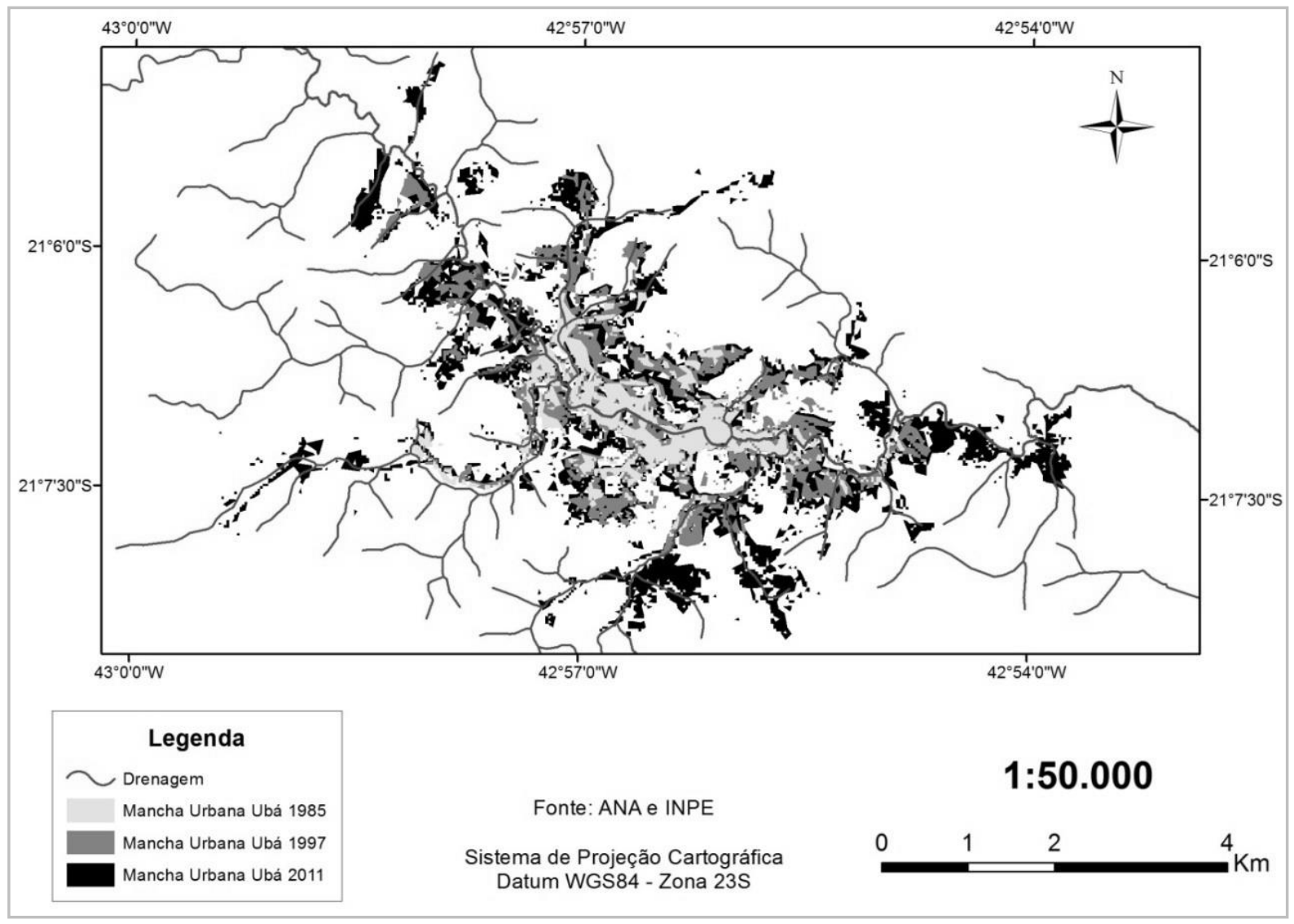

Fonte: Santos (2013).

A comparação entre as Figuras 7 e 8 é um exemplo dessa modificação da paisagem urbana ao longo de cinco décadas. Nota-se como as ocupações ao longo do Ribeirão Ubá cresceram com a calha do curso sendo praticamente canalizada. Além disso, o bairro Jardim Glória, na década de 1960, ocupava da baixa a média encosta, sendo que em 2014 ele se expandiu para a alta encosta e topo de morro, se encontrando com o bairro São Domingos, localizado no outro lado do interflúvio, que também se expandiu nessa direção. Esse tipo de situação vem se tornando comum ao longo de toda a cidade, devido aos vários loteamentos que estão sendo implantados. 
Figura 7. Área central de Ubá na década de 1960.

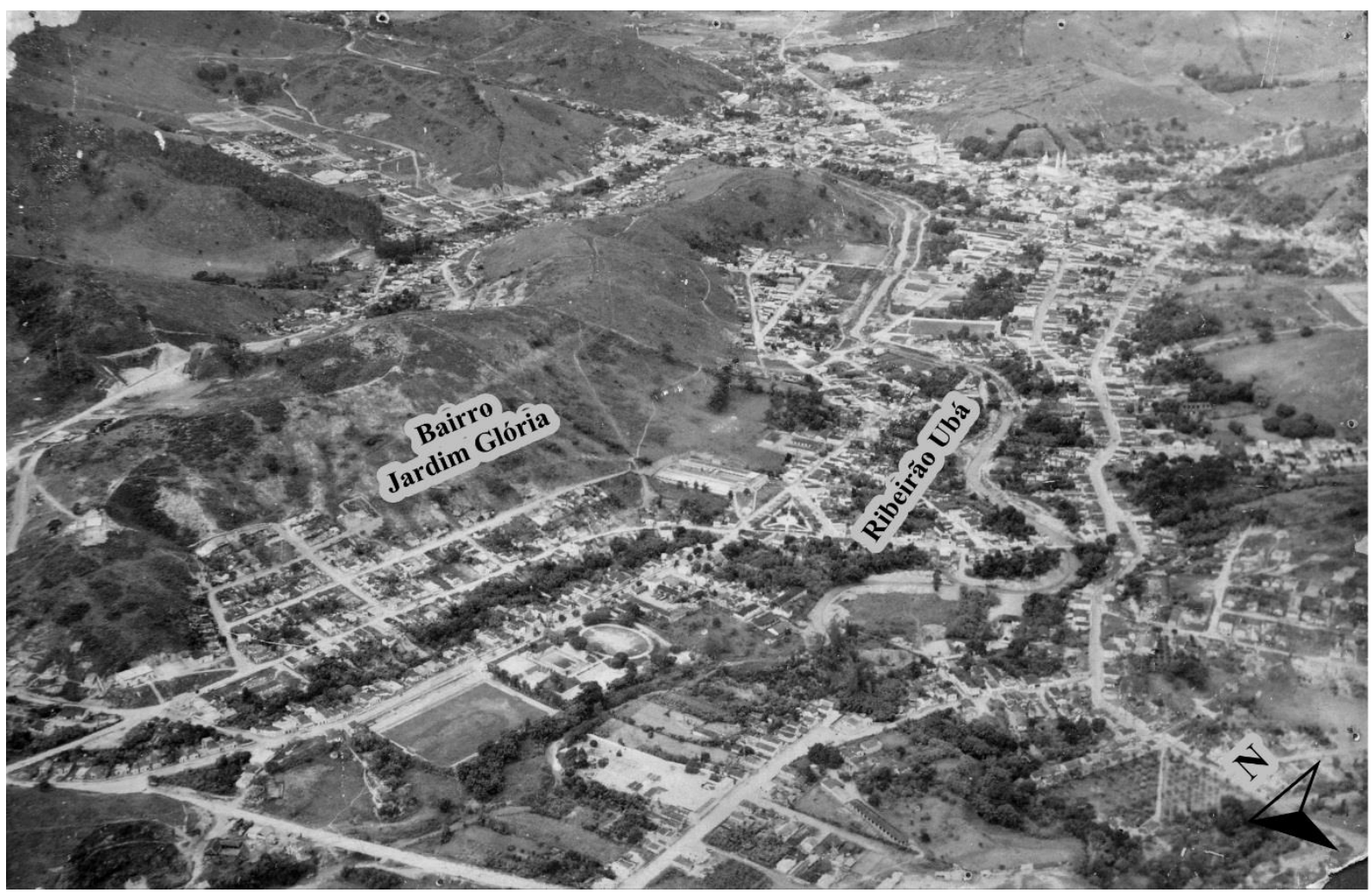

Fonte: Fotografia cedida pelo Arquivo Histórico de Ubá e adaptada pelos autores.

Figura 8. Área central de Ubá em 2014.

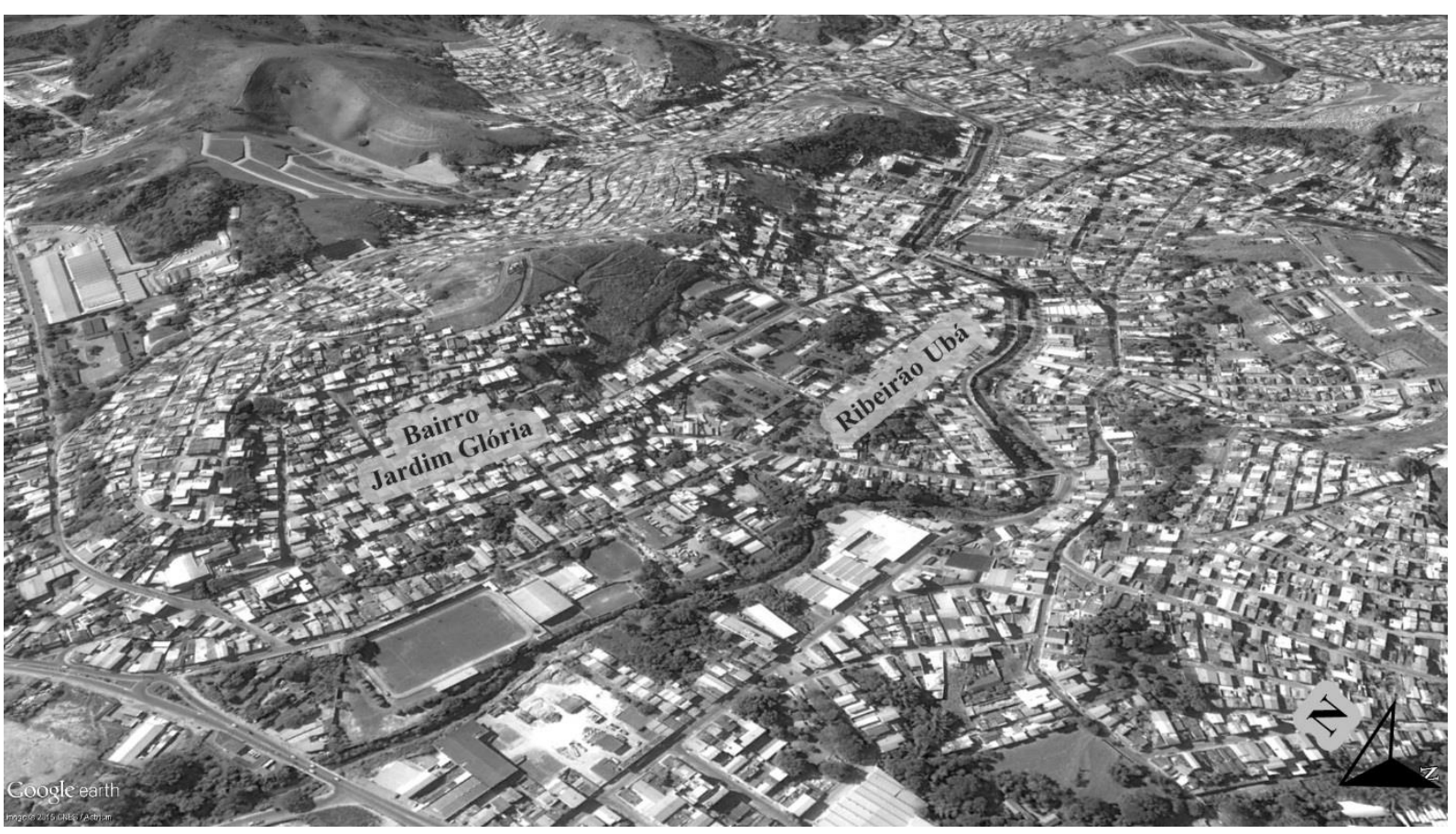

Fonte: Imagem extraída do software Google Earth Pro e adaptada pelos autores. 


\section{Considerações finais}

É de grande importância conhecer a evolução demográfica e o crescimento urbano de qualquer município. No caso de Ubá, viu-se que suas principais atividades econômicas influenciaram a dinâmica demográfica não somente no interior do território municipal, mas também em sua microrregião. O êxodo rural das populações do próprio município e a emigração de pessoas dos municípios vizinhos são fatores que colaboraram para o aumento de sua população urbana. Como consequência, houve a expansão da área urbana, iniciando-se nos vales fluviais, nas margens dos cursos d'águas, e posteriormente avançando para as encostas adjacentes, ocupando vertentes com declividades acentuadas e até mesmo áreas de topos de morros.

A relevância de conhecer tais fatos reside, por exemplo, no entendimento de alguns problemas ambientais que a cidade e todo o município passam atualmente. Exemplos são os frequentes casos de inundações na cidade. Ubá apresenta tais problemas desde o início de sua ocupação, pois esta se deu próximo aos cursos d'águas, nas planícies de inundações. Serve como exemplo uma notícia apresentada pelo jornal Folha do Povo, do dia 19 de janeiro de 1919, encontrada no Arquivo Histórico Municipal, que relata uma grande inundação ocorrida nas margens do Ribeirão Ubá, principal curso d'água do município.

$\mathrm{Na}$ medida em que a cidade foi crescendo e se expandindo, ocupando áreas de encostas e topos de morros, começaram a agravar as enxurradas e os movimentos de massa. A abertura de loteamentos e a construção de imóveis, que retiram uma grande quantidade de solo, expondo os horizontes mais profundos e os deixando mais expostos, intensificam os processos erosivos nessas áreas de interesse do mercado imobiliário, ainda mais quando não acompanhadas de obras de infraestrutura, como as galerias pluviais e redes de esgoto. Outros problemas podem ser citados, como a questão de 
abastecimento público de água, que geralmente se torna insuficiente nas épocas com menores volumes de chuvas.

Portanto, os estudos que relacionam as questões econômicas com as demográficas podem contribuir para o entendimento de dilemas ambientais ou processos que se passam em determinada cidade ou município. Problemas ambientais podem ter parte de suas origens nos aspectos históricos ligados à evolução econômica e demográfica de certa localidade.

No entanto, nos estudos em que se relaciona a pressão demográfica sobre o ambiente, deve-se tomar o cuidado de não reduzir a pesquisa a uma relação unidimensional, que frequentemente relaciona a pressão de números populacionais sobre os recursos naturais. "A pressão demográfica já foi responsabilizada por todos os males do mundo moderno". (HOGAN, 1991, p. $61)$.

Há outros fatores envolvidos na ocupação do espaço tão importantes quanto o crescimento demográfico e que interferem de forma negativa no ambiente (HOGAN, 1991). Não é só a quantidade de pessoas que habita certo local que determina a exploração de recursos e a degradação ambiental, mas também a forma como a ocupação desse local aconteceu historicamente e a política de habitação estabelecida nele, além de interesses econômicos, políticos e sociais envolvidos no processo.

Este artigo tem como objetivo dar suporte aos futuros trabalhos sobre a cidade e que atentem para a relação sociedade e ambiente. Futuras pesquisas devem ter maior aprofundamento, indo além dos aspectos econômicos e demográficos aqui avaliados.

\section{Agradecimentos}

O presente trabalho foi realizado com apoio da Coordenação de Aperfeiçoamento de Pessoal de Nível Superior - Brasil (CAPES) - Código de Financiamento 001. 


\section{Referências}

ALBINO, A. A. Uma abordagem evolucionária do APL moveleiro de Ubá: competitividade e políticas públicas estratificadas. 2009. 176 f. Dissertação (Mestrado em Administração) - Universidade Federal de Viçosa, Viçosa, 2009. Disponível em: < http://www.locus.ufv.br/handle/123456789/1930?show=full>. Acesso em: 14 nov. 2015.

ALVES, G. del P. Eficiência produtiva e indicadores financeiros das empresas moveleiras de Ubá-MG. 2009. 76 f. Dissertação (Mestrado em Economia) - Universidade Federal de Viçosa, MG, 2009. Disponível em: <http://www.locus.ufv.br/bitstream/handle/123456789/3244/texto\%20comple to.pdf?sequence=1\&isAllowed=y>. Acesso em: 14 nov. 2015.

ANDRADE, M. C. de. Aspectos geográficos da região de Ubá. Anais da associação dos geógrafos brasileiros, São Paulo, Avulso n. 1, 1961.

BRITO, F. O deslocamento da população brasileira para as metrópoles. Estudos Avançados, São Paulo, v. 20, n. 57, 2006. https://doi.org/10.1590/S0103-40142006000200017 AMORIM FILHO, O. B.; RIGOTTI, J. I. R.; CAMPOS, J. Os níveis hierárquicos das cidades médias de Minas Gerais. RA'EGA, Curitiba, v. 13, 2007. https://doi.org/10.5380/raega.v13i0.7784

HOGAN, D. J. Crescimento demográfico e meio ambiente. Revista Brasileira de Estudos de População, Campinas, v. $8, \quad$ n. 1/2, p. 61-71, 1991. Disponível em: <http://www.rebep.org.br/index.php/revista/article/view/524>. Acesso: 06 set. 2014.

IBGE. Instituro Brasileiro de Geografia e Estatística. 1970. Censo Demográfico. Disponível em:

<https://biblioteca.ibge.gov.br/visualizacao/periodicos/69/cd_1970_v1_br.pdf> Acesso em: 24 ago. 2019.

IBGE. Instituto Brasileiro de Geografia e Estatística. 2006. Censos Agropecuários, 1970, 1975, 1980, 1985, 1995, 2006. Disponível em: < https://www.ibge.gov.br/estatisticas/economicas/agricultura-e-

\%C3\%AAspecuaria/21814-2017-censo-agropecuario.html?=\&t=sobre>. Acesso em: 15 mai. 2019.

IBGE. Instituto Brasileiro de Geografia e Estatística. 2010. Censo Demográfico 2010. Disponível em: <https://www.ibge.gov.br/estatisticas/sociais/populacao/9662censo-demografico-2010.html?edicao=9666\&t=sobre $>$. Acesso em: 15 mai. 2019. IBGE CIDADES. Instituto Brasileiro de Geografia e Estatística. 2015. Disponível em: <http://www.cidades.ibge.gov.br/xtras/home.php>. Acesso em: 3 out. 2014.

IBGE. Instituto Brasileiro de Geografia e Estatística. Região de influência das cidades. Rio de Janeiro: IBGE, 2008. 201 p. Disponível em: <http://www.ibge.gov.br/home/geociencias/geografia/regic.shtm?c=6 >. Acesso em: 18 set. 2014.

IPEADATA. Instituto de Pesquisa Econômica Aplicada. 2014. Disponível em: <http://www.ipeadata.gov.br/>. Acesso em: 23 jan. 2015.

OLIVEIRA, P. R. S. de et al. Cadeia produtiva da movelaria: polo moveleiro de Ubá. Viçosa, MG: U.R. EPAMIG ZM, 2010. 66 p. Disponível em: <http://www.ciflorestas.com.br/arquivos/doc cadeia uba 22444.pdf>. Acesso em: 25 ago. 2019.

OLIVEIRA JÚNIOR, A. de. Instituição, espaço e desenvolvimento: o caso do Pólo Moveleiro de Ubá, MG. 2011. 153 f. Tese (Doutorado em Geografia) - Universidade Federal 
do Rio de Janeiro, Rio de Janeiro, 2011. Disponível em: $<$ http://objdig.ufrj.br/16/teses/775967.pdf>. Acesso em: 23 mar. 2018.

PREFEITURA MUNICIPAL DE UBÁ (PMU). Plano de gestão dos serviços de abastecimento de água potável e esgotamento sanitário do município de Ubá. Ubá,

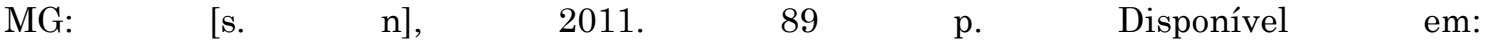
<http://www.uba.mg.gov.br/abrir arquivo.aspx/Consulta Publica?cdLocal=2 \&arquivo=\%7B84133B8B-ECDD-E664-5ED8-2EAE1E7E1EA2\%7D.pdf $>$.

Acesso em: 15 jan. 2015.

SANTOS, V. J. Episódios pluviais intensos: um estudo de caso sobre o município de Ubá/MG. 2013. 116 f. Monografia (Especialização em Climatologia Urbana) - Universidade Federal de Viçosa, Viçosa, MG. Disponível em: <http://www.geo.ufv.br/wpcontent/uploads/2013/08/Vitor-Juste-dos-Santos.pdf>. Acesso em: 17 dez. 2014. SILVA, A. R. da. O papel das políticas públicas no desenvolvimento sustentável do arranjo produtivo moveleiro de Ubá-MG. 2008. 144 f. Dissertação (Mestrado em Administração) - Universidade Federal de Viçosa, Viçosa, 2008. Disponível em: <http://www.locus.ufv.br/bitstream/handle/123456789/1923/texto\%20comple to.pdf? sequence $=1>$. Acesso em: 30 nov. 2015.

INTERSIND. Sindicato Intermunicipal das Indústrias Moveleiras de Ubá. 2014. Disponível em: <http://www.ubamoveisdeminas.com.br/historico.php>. Acesso em: 30 nov. 2015 . 